\title{
Midscale food value chains: An introduction
}

\author{
G. W. Stevenson (University of Wisconsin), Kate Clancy (University of Minnesota), \\ Robert King (University of Minnesota), Larry Lev (Oregon State University), \\ Marcia Ostrom (Washington State University), and Stewart Smith (University of Maine)
}

Citation: Stevenson, G. W., Clancy, K., King, R., Lev, L., Ostrom, M., \& Smith, S. (2011). Midscale food value chains:

An introduction. Journal of Agriculture, Food Systems, and Community Development, 1(4), 27-34.

http://dx.doi.org/10.5304/jafscd.2011.014.007

Copyright (C) 2011 by New Leaf Associates, Inc.

\begin{abstract}
This introductory discussion positions midscale food value chains as business models for a "third tier" in the U. S. food system, distinct from direct marketing to local consumers and global marketing of agricultural commodities. Responding to a growing demand for food that is differentiated from conventional products, midscale food value chains are developing strategic business alliances among small and medium sized farms or ranches and other agri-food enterprises. These supply chain alliances: (a) handle significant volumes of highquality, differentiated food products; (b) operate effectively at regional, multistate levels; and (c) distribute profits equitably among the strategic partners. Value chain business models place emphasis on both the values associated with the food and the values associated with the business relationships within the food supply chain. Farmers and ranchers are treated as strategic partners, not as interchangeable input suppliers. Midscale food
\end{abstract}

The authors are members of a research working group associated with the National Agriculture-of-the-Middle Initiative (www.agofthemiddle.org). value chains employ two distinct, multifarm marketing strategies: direct-to-wholesale and directto-consumer. Both marketing strategies are based on organizational structures that achieve the necessary volumes of high-quality, differentiated food by aggregating product from multiple farms or ranches. The introduction concludes with a discussion of the challenges associated with developing successful midscale food value chains and of needed research and public policies to support the growth of this third tier.

\section{Keywords}

agriculture of the middle, differentiated products, equitable distributions, midscale, multifarm aggregation, strategic partnerships, third tier, value chains

\section{Current Dynamics in the U. S. Food System: Rebuilding the Middle}

The U.S. food system increasingly is following two marketing paths. On the one hand, some farm and food enterprises thrive by selling food products directly to local consumers. On the other hand, large firms establish supply chains that move food 
Figure 1. The Disappearing Middle: Change in Farm Numbers by Sales Category, 1997-2007*

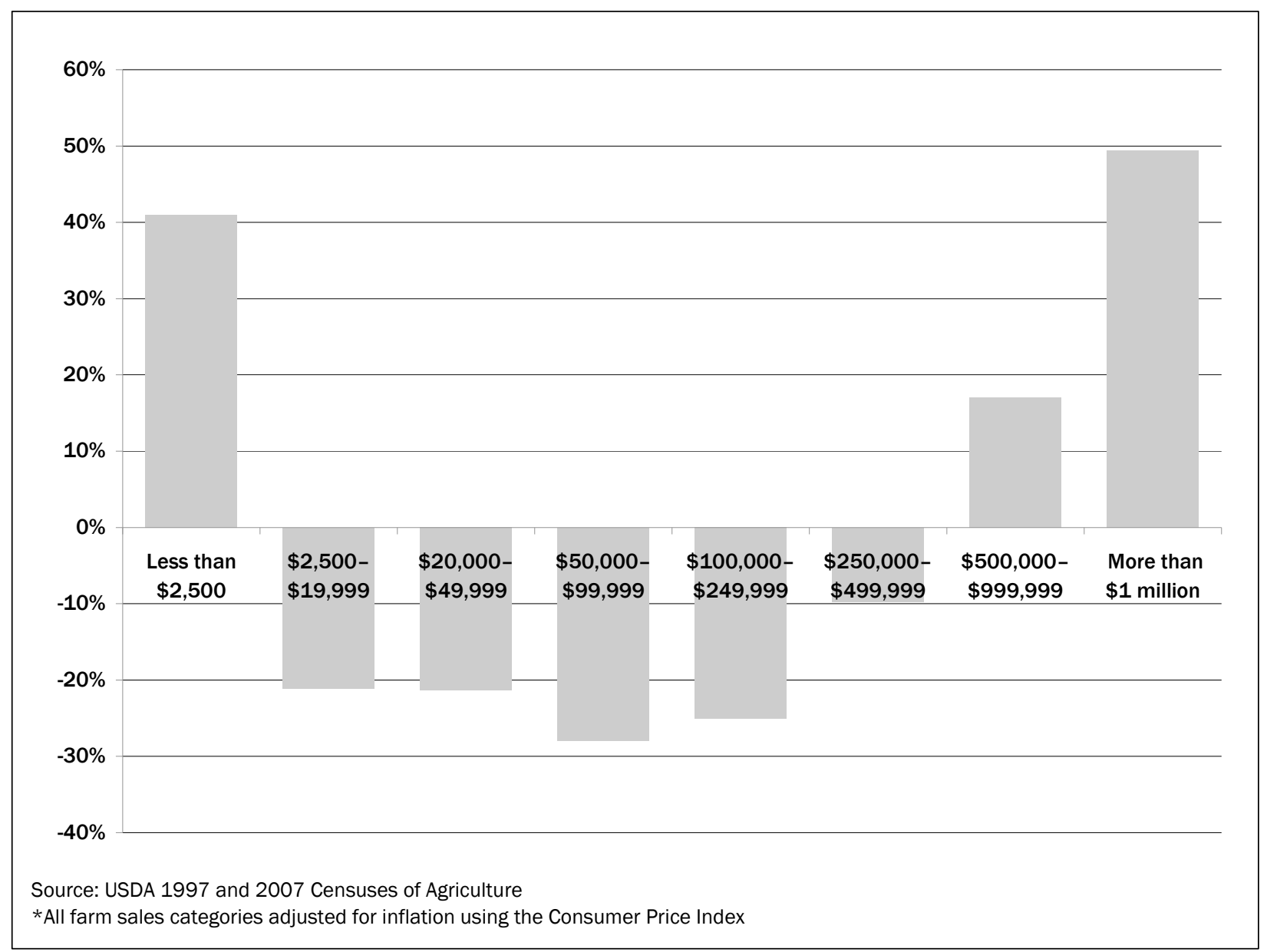

commodities around the world (Kirschenmann, Stevenson, Buttel, Lyson, \& Duffy, 2008).

Many small and medium-sized farms and ranches ${ }^{1}$ are ill-served by these two marketing options. These farms are often too small to successfully compete individually in international agriculture commodity markets, while being too large and/or poorly positioned to directly market food to local consumers. While very small and very large farms have increased in numbers, farms of the middle

\footnotetext{
${ }^{1}$ Most of these farms and ranches fall into either the "farming occupation farms" or "large family farms" categories of the USDA Farm Typology (USDA 2000). In statistical terms, most generate gross annual sales of between US $\$ 50,000$ and US $\$ 700,000$. The term "farms of the middle" will be used in the following discussion to identify these small and mediumsized farms and ranches.
}

have been disappearing for decades (Buttel \& LaRamee, 1991; Duffy, 2008). Figure 1 shows the national disappearance profile from 1997 to 2007. Despite the loss, farms of the middle still constitute nearly $20 \%$ of all farms and nearly $25 \%$ of all farm sales (USDA 2009). In addition to their poor fit with available markets, other causes posited for the decline of farms of the middle include lower rates of return on equity compared to very large farms, inability to take full advantage of larger equipment and economies of scale, improvements in information technology that enable commodityscale farmers to manage large and complex enterprises, and the impacts of federal farm programs (Hoppe, MacDonald, \& Korb, 2010).

Historically farms of the middle have been the backbone of the agricultural sector of many rural 
and peri-urban areas of the country. These farms remain important for a number of reasons.

Through their ownership, farms of the middle have stewardship responsibilities for nearly one-half of all agricultural lands in the U.S. (Duffy, 2008). A lineage of research indicates that these farms are a key element for increasing socioeconomic vitality in agriculturally dependent communities (Goldschmidt, 1978; Lyson, 2004; Strange, 1989). The renewed vitality of these farms is critical for a diverse, decentralized, and resilient structure of agriculture that is important for national food security (Walker \& Salt, 2006).

Recognizing the importance of rebuilding a vital agriculture of the middle in the U.S., a national task force was assembled in 2003 that was composed of farmers, academics, business persons, leaders of nonprofit organizations, and USDA employees. The 22-member task force formulated a threefold approach to rebuilding this important middle sector: (1) new business and marketing strategies, (2) public policy changes; and (3) research and education support. ${ }^{2}$ With the goal of developing these three components, the National Agriculture of the Middle Initiative replaced the task force in 2004. The initiative is led by a seven-person coordinating committee. ${ }^{3}$

As part of the initiative's first approach, several onthe-ground supply chain initiatives are pursuing and testing new business and marketing strategies. A public policy reform agenda has been developed, primarily centered on the federal farm bill. The research component of the initiative is organized through a USDA-sponsored, multistate project composed of approximately 20 researchers from land-grant universities as well as other institutions and research organizations. ${ }^{4}$

\footnotetext{
${ }^{2}$ For a detailed discussion of the national task force's threefold approach, see the Key Documents section of the agriculture of the middle website at http://www.agofthemiddle.org

${ }^{3}$ The composition of the coordinating committee is available at http://www.agofthemiddle.org

${ }^{4} \mathrm{~A}$ full description of the current multistate project is available at http://gu.umd.edu/lgu v2/pages/showInfo.cfm? $\underline{\text { trackID }=12816 \& C F I D=102634166 \& C F T O K E N=10145002}$
}

In the initiative's beginning, several researchers focused their attention on "value chain" business models. These researchers drew from the business literature of other sectors such as automobile and consumer electronics where value chains are defined as "long-term networks of partnering business enterprises working together to maximize value for the partners and end customers of a particular product or service" (Dyer, 2000; Handfield \& Nichols, 2002). In the business literature, these long-term interorganizational relationships are also called "extended enterprises," "strategic alliances," "integrated value systems," and "value-added partnerships" (Dyer, 2000; Handfield \& Nichols, 2002).

The research also identified significant market openings for these threatened farms of the middle. The research group's primary hypothesis is that shifts are occurring in the country's food system that can provide significant opportunities to prosper for a re-formed agriculture of the middle. Surveys indicate that a growing number of consumers are committed to purchasing food that is unique and differentiated from conventional products. Products may be differentiated by attributes such as organic, grass fed, or regionally sourced (Brady \& O’Brady, 2008) or, following Europe's lead in the concept of fair trade, by emphasizing issues of social justice and environmental responsibility (Jaffee, Kloppenburg, \& Monroy, 2004).

Progressive leaders in some medium to large food corporations recognize the confluence of their interests with the rebuilding of an agriculture of the middle that can supply these unique products. For example, the former CEO of a large food-service company describes customers as wanting memorable, high-quality food, produced with a farming story they can support, and brought to them through supply chains they can trust (Schnieders, 2004). Restaurants and cafeterias of public and private institutions, e.g., health care facilities, schools, universities, and corporations, are particularly receptive to these types of food products, as are regional supermarkets that seek to 
differentiate themselves from their larger national competitors.

Farms of the middle have a potential comparative advantage in these emerging markets. As mentioned earlier, individual direct-marketing farms cannot produce the necessary volumes required for these new markets, and commodity farms are not designed to produce the necessary quality and differentiation. Farms of the middle, on the other hand, have both the capacity and flexibility to collaborate with each other and with other supply chain partners to respond to these expanding markets.

Business models and public policies are needed to effectively connect and support agricultural producers of the middle as they engage these growing markets for differentiated, higher-value food products. Midscale food value chains are one promising business model.

\section{Midscale Food Value Chains: Business Models for a Third Tier in the U. S. Food System}

Midscale food value chains are positioned as an alternative to local direct marketing and global commodity marketing: a "third tier." Ideal midscale value chains are strategic business alliances among farms of the middle and other agrifood enterprises that: (a) handle significant volumes of high-quality, differentiated food products, (b) operate effectively at multistate, regional levels, ${ }^{5}$ and (c) distribute profits equitably among the strategic partners. Value chain business models place emphasis on both the values associated with the food and on the values associated with the business relationships within the food supply chain. The overall business model of value chains features close cooperation among strategic partners within the chain and competition between chains doing business in a

\footnotetext{
${ }^{5}$ For purposes of this discussion, "regional" is defined as multistate. For a more in-depth exploration of regional food systems, see Clancy \& Ruhf, 2010.
}

given product or service sector (Stevenson \& Pirog, 2008). ${ }^{6}$

In many conventional supply chains, business relationships are framed in win-lose terms. Relationships are constructed as competitive, even adversarial, whereby each company seeks to buy as cheaply and sell as expensively as possible. While this model may be appropriate for undifferentiated commodity supply chains, it does not perform well for value chains where differentiation is based primarily on product and relationship qualities. ${ }^{7}$ Framed in win-win terms, value chains are based on commitments to the welfare of all partners in the supply chain, including fair profits, fair wages, and business agreements of appropriate extended duration. ${ }^{8}$ Given the interdependence in food value chains, participants have a strategic self-interest in the performance and well-being of the other partners. In food value chains farmers and ranchers are treated as strategic partners, not as interchangeable (and exploitable) input suppliers.

Midscale food value chains distinguish themselves from both direct and commodity marketing supply chains in combining quality and volume, in key business relationships, and in energy savings. For example, farmers and ranchers in these food value chains are positioned as "price negotiators," as distinct from "price setters" in direct marketing, and as "price takers" in commodity marketing systems. Their good fit with multistate levels of operation makes these midscale food value chains potentially effective contributors to regional economic development (Marsden, Banks, \&

\footnotetext{
${ }^{6}$ Employing an Internet search methodology, in 2007 researchers identified 75 food supply chains in three regions of the country that possessed some characteristics of midscale food value chains (Hoshide, 2007).

${ }^{7}$ For a discussion regarding the functions of cooperation in value chains, see Dyer, 2000, or Handfield \& Nichols, 2002.

${ }^{8}$ For a more detailed discussion comparing win-win with winlose business relationships, see appendix A of the four value chain case studies available at http://www.agofthemiddle.org ${ }^{9}$ Farmers and ranchers in successful value chains have reasonable calculations of their production costs and are able to negotiate prices based on acceptable profit margins above those costs. See the Lev and Stevenson article in this issue for examples and more details.
} 
Bristow, 2000). Furthermore, statewide or regional food distribution systems can offer valuable energy savings compared to local and global systems (Pirog, Van Pelt, Enshayan, \& Cook, 2001). Finally, midscale food value chains can contribute to a diverse, decentralized, and resilient structure of agriculture that is important for national food security (Walker \& Salt, 2006).

While midscale food value chains distinguish themselves from the two other marketing strategies, they also share key characteristics with each. As with direct marketing, value chains share an emphasis on high-quality food products and identification of producers. In common with commodity marketing, value chains recognize the importance of efficient supply-chain management and logistics. ${ }^{10}$

The midscale food value chain model plays out in two distinct versions based on marketing strategies: (1) Direct-to-wholesale ${ }^{11}$ marketing to regional supermarkets and food service companies, and (2) Direct-to-consumer food marketing to customers who are the eaters of the products. Both marketing strategies are based on business models and organizational structures that achieve the necessary volumes of high-quality, differentiated food by aggregating product from multiple farms or ranches. Scale is achieved through collective action rather than through increasing the size of individual farms.

These versions of midscale food value chains differ in marketing strategy and in types of farms involved. The direct-to-wholesale strategy enables small and medium-sized commodity producers to differentiate, aggregate, and collectively market through direct wholesaling networks. For examples of successful direct-to-wholesale food value chains,

\footnotetext{
10 The concept of "regional food hubs" is a newly revitalized idea that could significantly facilitate the logistical performance of some midscale food value chains (Barham, 2010). ${ }^{11}$ Direct-to-wholesale moves products through supermarket and food service distribution systems as well as distribution systems that use direct store delivery to multiple stores. Particularly important in direct-to-wholesale food value chains is retention of the product's original identity and/or brand throughout the supply chain.
}

see the four case studies on the website indicated in footnote 8 and the Lev and Stevenson article in this volume.

The second midscale food value chain strategy enables smaller producers of differentiated products to aggregate and collectively market through multifarm, scaled-up, direct-to-consumer networks.. Examples include multifarm community supported agriculture farms (CSAs) and multifarm Internet sales enterprises. ${ }^{12}$ As a market diversification strategy, individual direct-marketing farms may choose to participate in both direct-toconsumer and direct-to-wholesale value chains.

\section{Challenges in Developing Midscale Food Value Chains}

There are significant challenges associated with developing successful midscale food value chains. ${ }^{13}$ A great deal depends on the favorable confluence of a number of factors. Research indicates that sustainable midscale food value chains successfully address the following kinds of challenges ${ }^{14}$ :

- Finding appropriate value chain partners and developing mechanisms for value chain decision-making, transparency and trust;

- Determining effective strategies for product differentiation, branding, and regional identity;

- Determining appropriate strategies for product pricing based on understanding true cost structures;

\footnotetext{
12 Good examples include Full Circle Farm and Good Earth Farms. Full Circle Farm is a multifarm CSA that aggregates product from nine Washington organic farmers and delivers food boxes weekly to over 5,000 eaters located from Seattle to Alaska (www.fullcirclefarm.com). Good Earth Farms is a multifarm Internet sales enterprise that aggregates organic, pasture-raised meat products from six Wisconsin farms and delivers frozen meat to customers throughout the country via overnight delivery (www.goodearthfarms.com).

${ }^{13}$ For a similar conclusion based on an analysis of European value chains, see Marsden, Banks, \& Bristow, 2000.

${ }^{14}$ See the Lev and Stevenson article in this issue for a discussion of how four successful value chain businesses address these challenges.
} 
- Acquiring adequate capitalization and competent management;

- Developing effective quality control and logistical systems; and

- Developing economic power for value chain negotiations.

\section{Policy and Research Support}

In the 2008 farm bill changes were made that benefit midsized enterprises, including a $10 \%$ setaside in the USDA's Value Added Producer Grant program for the development of midtier food value chains, and also a revision of the Business and Industry Loan Program to make local and regional food businesses explicitly eligible for B\&I loans and loan guarantees. Needed now is a move by other USDA lending programs to broaden their outreach and lending portfolios to include more midsized farms that are developing new markets. The USDA also should develop crop insurance and disaster-relief programs that compensate farmers who are producing organic or other differentiated crops at their documented market price. At press time, other policy items are under consideration for inclusion in the 2012 farm bill discussion. Given the current political atmosphere associated with the federal budget, significant restraints exist related to new or expanded policies or programs that involve increased funding.

Since the concept of midscale food value chains has been highlighted by the National Agriculture of the Middle Initiative only in the last 7 to 8 years, there is a small but growing base of research for supply chain actors to utilize. ${ }^{15}$ Much of this

${ }^{15}$ In addition to the case studies available at http://www.ag ofthemiddle.org, see the following case studies:

- From competition to cooperation: V alue chains as a tool for agricultural development, by Adam Diamond and James Barham, at http://www.ams.usda.gov/AMSv1.0/getfile? $\underline{\mathrm{dDocName}}=$ STELPRDC5087761 \&acct $=$ wdmgeninfo;

- SYSCO's journey from supply chain to value chain: 2008-2009 final report, at http://www.wallacecenter.org/ourwork/Resource-Library/InnovativeModels/Sysco $\% 20$ Case $\% 20$ Study $\% 202009$.pdf; and research is evidenced through articles in this issue. Within the USDA's new National Institute of Food and Agriculture (NIFA), the SARE program and the competitive grants program on the Prosperity of Small and Medium-Sized Farms have funded much of this research, but these programs themselves are funded at levels far below demand. A recent report offers an important but still short list of needed research projects that will contribute important information to value chain actors and other interested parties (Clancy \& Lehrer, 2010). These include research on:

- The development of new farming and ranching systems that produce high-quality and differentiated food, reduce dependence on petroleum, and are resilient to climate shocks;

- Key economic components of midscale food value chains, including profit margins for food processors, distributors, and retailers, as well as long-term producer income comparisons with income from commodity prices;

- How partners come together to explore and develop midscale food value chains;

- How the dynamics inside food value chains are different when the driver of the chain is different, e.g., producer-driven versus distributor- or retail-firm-driven value chains;

- How to increase the participation of food consumers in value chain decision-making;

- How midscale food value chains contribute to regional economic development;

- Regional value chains in the Northeast: Findings from a survey, by Kate Clancy and Kathy Ruhf, at http://api.ning.com/ files/WAFzvztbJNjQVIglsHHegv*VwDfNbVjqOfGweBy GwziZ7kR1j-naG721B9E0rHkx88*OpwwE87k0VuMFS WdQoucWVWFSowT/NESAWGValueChainsReport127 10updated.pdf 
- How midscale food value chains can interface with emerging regional "food hubs"; and

- How existing public policies can be combined to support the development of midscale food value chains.

\section{Conclusions}

The research and experiences reported in the rest of this issue suggest that successful mid-scale food value chains are built on three foundations. The first is appropriate volumes of high-quality, differentiated, market-engaging food products; coupled with value-adding stories of people, land, and practices. The second foundation involves strategic business partnerships based on trusting, transparent, and win-win relationships. Finally, successful food value chains exhibit effective supply chain management and logistics, including product marketing, aggregation, processing, distribution and accounting. Future research is expected to deepen our understandings of these promising new food business models and supply chains.

\section{References}

Barham, J. (2010). Getting to scale with regional food hubs. Available at http:/ / kyf.blogs.usda.gov/2010/ 12/14/getting-to-scale-with-regional-food-hubs/

Brady, E.\& O’Brady, C. (2008). Consumer considerations and the agriculture of the middle. In T. Lyson, G. Stevenson, \& R. Welsh (Eds.), Food and the mid-level farm: Renewing an agriculture of the middle. Cambridge, MA: The MIT Press.

Buttel, F., \& LaRamee, P. (1991). "The disappearing middle": A sociological perspective. In W. Friedland, L. Busch, F. Buttel, \& A. Rudy (Eds.), Towards a new political economy of agriculture. Westview Special Studies in Agriculture and Policy. Bellevue, TN: Westview Press.

Clancy, K., \& Lehrer, N. (2010). A priority research agenda for agriculture of the middle. Available at http://www.agofthemiddle.org

Clancy, K., \& Ruhf, K. (2010). Is local enough? Some arguments for regional food systems. Choices, 25(1). Available at http://www.choicesmagazine.org/ magazine / article.php?article $=114$
Duffy, M. (2008). The changing status of farms and ranches of the middle. In T. Lyson, G. Stevenson, \& R. Welsh (Eds.), Food and the mid-level farm: Renewing an agriculture of the middle. Cambridge, MA: The MIT Press.

Dyer, J. (2000). Collaborative advantage: Winning through extended enterprise supplier networks. New York: Oxford University Press.

Goldschmidt, W. (1978). As you sow: Three studies in the social consequences of agribusiness. Montclair, NJ: Allanheld, Osman. (Original work published 1947.)

Handfield, R., \& Nichols. E. (2002). Supply chain redesign: Transforming supply chains into integrated value systems. Upper Saddle River, NJ: Prentice Hall.

Hoppe, R., MacDonald, J., \& Korb, P. (2010). Small farms in the United States: Persistence under pressure. EIB-63. United States Department of Agriculture, Economic Research Service. Available at http://www.ers.usda.gov/Publications/EIB63/

Hoshide, A.(2007). Values-based and value-added value chains in the Northeast, Upper Midwest, and Pacific Northwest. Available at http://www.agofthemiddle.org

Jaffee, D., Kloppenburg, J., \& Monroy, M. (2004). Bringing the "moral charge" home: Fair trade within the north and within the south. Rural Sociology, 69(2), 169-197. http://dx.doi.org/ $\underline{10.1526 / 003601104323087561}$

Kirschenmann, F., Stevenson, G., Buttel, F., Lyson, T., \& Duffy, M. (2008). Why worry about the agriculture of the middle? In T. Lyson, G. Stevenson, \& R. Welsh (Eds.), Food and the mid-level farm: Renewing an agriculture of the middle. Cambridge, MA: The MIT Press.

Lyson, T. (2004). Civic agriculture: Reconnecting farm, food, and community. Medford, MA: Tufts University Press.

Marsden, T., Banks, J. \& Bristow, G. (2000). Food supply chain approaches: Exploring their role in rural development. Sociologia Ruralis, 40(4), 424-438. http://dx.doi.org/10.1111/1467-9523.00158

Pirog, R., Van Pelt, T., Enshayan, K., \& Cook, E. (2001). Food, fuel, and freeways: An Iowa perspective on how far food travels, fuel usage, and greenhouse gas emissions. Ames, IA: Leopold Center for Sustainable Agriculture. 
Schnieders, R. (2004). Presentation at Georgetown University's Corporate Counsel Institute. Available at http://www.agofthemiddle.org/archives/ 2004/08/key documents.html

Stevenson, G., \& Pirog, R. (2008). Values-based supply chains: Strategies for agrifood enterprises of the middle. In T. Lyson, G. Stevenson, \& R. Welsh (Eds.), Food and the mid-level farm: Renewing an agriculture of the middle. Cambridge, MA: The MIT Press.

Strange, M. (1988). Family farming: A new economic vision. Lincoln, NE: University of Nebraska Press.
U.S. Department of Agriculture (USDA). (2000). ERS farm typology for a diverse agricultural sector. Economic Research Service. Available at http://www.ers.usda. gov/publications/aib759/aib759.pdf

U. S. Department of Agriculture (USDA). 2009. 2007 Census Report, Volume 1. National Agricultural Statistics Service. Available at http://www.agcensus.usda.gov/Publications/ 2007/Full_Report/index.asp

Walker, B., \& Salt, D. (2006). Resilience thinking. Washington, DC: Island Press. 